\title{
NOAS: HoUve IMPACTO PARA O SUS?
}

\author{
NOAS: WAS THERE IMPACT FOR SUS?
}

\author{
Silvana Souza da Silva Pereira ${ }^{(*)}$ \\ Marcus Vinícius Quito ${ }^{(*)}$
}

RESUMO

O Sistema Único de Saúde pode ser considerado como resultado de um processo de construção social, fruto da militância de inúmeros atores, interesses e peculiaridades numa dialética de agregação em determinados momentos e desagregação em outros. Busca apresentar considerações sobre o processo de operacionalização dos princípios do Sistema Único de Saúde, a partir de um breve resgate histórico e enfocando as normativas do final do século $\mathrm{XX}$ e início deste que foram apresentadas à sociedade e ofereceram sua contribuição ao processo de implementação do setor saúde. O enfoque principal foi a avaliação dos processos de habilitação dos estados e municípios segundo os critérios previstos na NOAS, e a efetividade desta norma enquanto orientadora dos princípios do SUS, particularmente quanto à regionalização dos serviços de saúde.

(*) Odontóloga. Especialista em Saúde Coletiva (UnB). Mestranda em Gestão de Sistemas e Serviços de Saúde (ENSP/FIOCRUZ). Diretora de Programa do Núcleo de Acompanhamento a Estados e Municipios da SAS-MS. Dentist. Specialist in Collective Health (Brasilia University). Master's degree student in Administration of Systems and Services of Health (ENSP/FIOCRUZ). Director of Program of the Nucleus of Attendance to States and Municipal Districts of Healthy Ministry of Health. silvana.pereira@saude.gov.br

$\left({ }^{\star \star}\right)$ Enfermeiro, Especialista em Enfermagem do Trabalho (UnB). Pesquisador do Núcleo de Estudos em Saúde Pública/NESP/UNB. Acadêmico de Direito. Assessor Técnico da Secretaria de Atenção à Saúde / Ministério da Saúde. Nurse, Specialist in Nursing of the Work (UnB). Researcher of the Nucleus of Studies in Public Health/NESP/UNB. Law student. Technical assistant of the General Office of Attention to the Health / Ministry of Health. marcus.quito@saude.gov.br. Entrada: 17/07/2003 - Aprovado: 22.9.2003. 


\title{
Descritores
}

Saúde Pública, Sistema de Saúde, Legislação Sanitária; SUS (BR).

\begin{abstract}
The Unique System of Health can be considered as a result of a process of social construction, fruit of the countless actors' militancy, interests and peculiarities in an aggregation dialectics in certain moments and disaggregation in other. Search to present considerations on the process of implementation of the beginnings of the Unique System of Health, starting from an abbreviation it rescues historical and focusing the normative of the end of the century $X X$ and beginning of this that you/they were presented to the society and they offered his/her contribution to the process of implementation of the section health. The main focus was the evaluation of the processes of qualification of the states and municipal districts according to the criteria foreseen in NOAS, and the effectiveness of this norm while advisor of the beginnings of SUS, particularly the as for the regionalization of the services of health.
\end{abstract}

\section{Keywords}

Public Health, System of Health, Sanitary Legislation.

A promulgação da CF/88 incluindo a saúde em seu texto, fruto da ativa militância do movimento da Reforma Sanitária, apresentou do ponto de vista formal o início do processo de organização do setor saúde até então desarticulado e periférico enquanto política pública. Mecanismos que garantiriam os princípios e diretrizes foram aos poucos sendo regulamentados e a partir deles processos organizacionais e, sobretudo, estruturantes foram sendo implementados ao longo dos quase dezesseis anos de Sistema Único de Saúde.

Diversos contextos políticos e econômicos foram percorridos até o presente momento em que encontramos um Sistema Único de Saúde. Observamos uma organização fortemente descentralizada e autônoma, que sente a necessidade de instrumentos para a qualificação da atenção, regulação, controle, fiscalização e avaliação de suas ações e serviços, repercutindo assim na ampliação de sua eficiência frente a toda sociedade. Considerando ainda, a real necessidade de minimizar as iniqüidades sociais e regionais tão presentes em nosso território.

Muitas iniciativas institucionais e jurídicas ofereceram, durante a década de 90 , subsídios diversos para a regulamentação dos princípios organizacionais do SUS. A concepção de saúde enquanto bem jurídico constitucionalmente protegido determinou ao Estado a necessidade de implementar os princípios e diretrizes apontadas na norma superior. Todos os movimentos institucionais implementados a partir da CF/88 incorporaram e ofereceram concretude à sua prescrita principologia. 
A universalidade diz do princípio em que todos os cidadãos têm os mesmos direitos aos serviços e ações de saúde, diferentemente do que ocorria enquanto eram os institutos, ou o INAMPS, em que somente os trabalhadores e familiares que contribuíam é que tinham direito ao acesso. Já a integralidade aponta aos serviços a serem prestados, que a saúde além de ser para todos sem exceção, deve ser a qualquer ação de saúde, pois o cidadão deve ter direito à integralidade de suas necessidades.

A eqüidade é tratar de forma diferente os desiguais, isto é, quem tiver maior necessidade deverá receber ações suficientes para que suas necessidades sejam atendidas. Somado a isso, a descentralização conforme o pacto federativo em que os níveis de município, estado e união não são hierárquicos e sim autônomos. O governo local, por estar mais próximo da realidade e da necessidade da população, possui maiores e melhores condições para exercer um planejamento mais respeitoso e eficiente conforme sua realidade local. "A descentralização associada à diretriz da gestão única resulta em três arranjos formais para o sistema de saúde: os sistemas municipais, estaduais e o nacional. Mas a integralidade e a hierarquização induzem à formação de outros subsistemas, como conseqüência da discussão intergestores"(1).

Dos princípios constitucionais, temos dilemas entre a universalidade $x$ eqüidade e regionalização $x$ descentralização. Esse último com grande repercussão para autonomia dos elementos federados e a crescente necessidade de ampliar e fortalecer as ações regionalizadas e hierarquizadas, buscando garantir o acesso universal e integral de forma ainda mais eficiente, racional e geograficamente possivel à população brasileira.

Um dos grandes marcos do processo de operacionalização do SUS foi dado em 19 de setembro de 1990, quando o Congresso Nacional decretou a Lei $n$. 8.080 , que dispôs sobre as condições para a promoção, proteção e recuperação da saúde, a organização e o funcionamento dos serviços correspondentes.

Esta lei foi responsável pela constituição do conjunto de ações e serviços de saúde prestados por órgãos e instituições públicas federais, estaduais e municipais, da administração direta e indireta, e das fundações mantidas pelo poder público, dispondo sobre a organização, a direção e a gestão do SUS; pela definição das competências das três esferas de governo; pelo funcionamento e pela participação complementar dos serviços privados de assistência à saúde; pela política de recursos humanos e dos recursos financeiros, da gestão financeira, do planejamento e do orçamento; e pela decisão de que as instituições privadas participem do SUS, mas de forma complementar.

Outro marco inicial aconteceu em 28 de dezembro de 1990, quando do decreto da Lei Complementar n. 8.142, que dispõe sobre a participação da comunidade na gestão do SUS (Conferência de Saúde e Conselho de Saúde) e sobre as transferências intergovernamentais de recursos financeiros na área da saúde (Fundo de Saúde, Conselho de Saúde, Plano de Saúde, Relatório de Gestão, Contrapartida de recursos para a saúde, Comissão de elaboração do Plano de Carreira, Cargos e Salários - PCCS).

(1) VIANA, A. L. D., HEIMANN, L. S., LIMA, L. D. de et al. "Mudanças significativas no processo de descentralização do sistema de saúde no Brasil". Cad. Saúde Pública, supl. v. 18, 2002, pp. 139-151. 
A política de recursos financeiros na saúde, a despeito das definições contidas na Constituição Federal de 1988 sobre as fontes que deveriam compor seu orçamento, avançou somente em 2002, com a promulgação de Emenda Constitucional $n$. 29, que define os percentuais mínimos dos recursos financeiros que a União, os Estados, o DF e os Municípios devem aplicar na saúde.

Com a decretação da chamada Lei Orgânica da Saúde outro desafio se apresentava: o de construir um caminho no sentido de padronizar ações, típicas de um sistema que se propõe a ser único, com efeitos jurídicos em um pais continental tomado de grandes diversidades regionais, e que de forma negociada e pactuada entre os diversos atores constituintes do sistema oferecesse meios consensuados para a melhor implementação do sistema.

O mecanismo de consenso entre os atores pode ser argumentado de forma resumida em função do sistema federativo envolver ao menos três idéias básicas: a) a idéia de igualdade entre os entes federados; b) a idéia de integridade, ou seja, de esferas autônomas; c) a idéia de cooperação, ou pacto. O federalismo é, portanto, o esforço de parceria para o estabelecimento de uma unidade entre os seus entes constituintes, sendo mutuamente reconhecida à igualdade e a integridade de cada um destes.

"Dessa forma, na década de 1990, o governo federal edita sucessivas Normas Operacionais Básicas (NOB's) portarias ministeriais, a fim de instruir e regular a nova organização do sistema, cujos conteúdos abrangem: definição das formas de transferência de recursos interinstâncias de governo; definição das modalidades de pagamento dos serviços de saúde; instrução do processo de descentralização e de construção de uma rede de serviços capaz de operar com racionalidade sistêmica; definição dos tipos de assistência (básica, de média e alta complexidade) na oferta e definição do modelo de atenção, que articula ações de promoção, prevenção, cura e recuperação."(2)

"As NOB's não representam apenas estratégias de indução ou de constrangimento do processo de descentralização; ao contrário, passam a configurar outros espaços de pactuação de interesses na área da saúde, originando ordenamentos, além da emergência e do fortalecimento de novos atores, pela incorporação de inúmeros centros de poder na arena decisória da política." ${ }^{3)}$

Goulart(4) questiona "se o SUS seria o mesmo sem as supostas amarras que as NOB's vêm tecendo; ou ainda se o processo desejável de pactuação entre as esferas de governo não viria sendo tolhido por uma excessiva formalização e centralização capitaneadas pelo gestor federal ao se arvorar de legislador, via NOB."

(2) LEVCOVITZ, E.; Lima, L; MACHADO, C. "Política de Saúde nos anos 90: relações intergovernamentais e o papel das Normas Operacionais Básicas". Ciência \& Saúde Coletiva, v. 6, n. 2, pp. 269-291, 2001.

(3) VIANA, A. L. D., HEIMANN, L. S., LIMA, L. D. de et al., op. cit., pp. 139-151.

(4) GOULART, F. de A. "Esculpindo o SUS a golpes de portarias - considerações sobre o processo de formulação das NOBs (comentário ao texto de Levcovitz et al., 2001). Ciência e Saúde Coletiva, , v. 6, n. 2, pp. 292-298, 2001. 
Levcovitz ${ }^{(5)}$ afirma que houve, através das NOB's, um grande avanço na autonomia dos municípios. Isto é questionado por outros autores principalmente no que diz respeito à utilização dos recursos financeiros. Há uma avaliação de que os municípios ficam 'como prisioneiros' das Normas, e que estas nem sempre refletem as características e necessidade de cada localidade.

Esta é uma questão controversa, pois há uma necessidade das três esferas de governo em identificar as formas e os caminhos a serem seguidos para a operacionalização dos princípios e diretrizes do SUS, instrumentos, normas, ou melhor ainda, pactos que esclareçam as prerrogativas, e à divisão de responsabilidades. O que se percebe, e que é consenso entre os diversos autores acima citados, é que grandes avanços aconteceram na saúde nos últimos anos, tanto no que diz respeito à descentralização, como na garantia e na qualidade do acesso às ações e serviços de saúde.

Cada uma das Normas teve um processo de elaboração/negociação, assim como características bem distintas, e abaixo será apresentada uma síntese de cada uma delas, sendo que haverá um detalhamento maior da NOAS 2002, pois é a que está em vigor. Resumidamente temos:

- NOB 1991: teve como característica fundamental a uniformização na modalidade de remuneração dos serviços prestados pelo setor público e privado;

- NOB 1993: deu início ao processo de descentralização da gestão da saúde, apesar da pouca adesão dos municípios. Teve o objetivo de fortalecer o papel dos municípios, em especial no que diz respeito ao primeiro nível de atenção;

- NOB 1996: acelerou o processo de descentralização através da redefinição das responsabilidades dos municípios, estados, do DF e da União, ampliando os mecanismos de repasse fundo a fundo da média e alta complexidade, e também da atenção básica. Foi criado o Piso de Atenção Básica - PAB, iniciativa que inaugurou a mudança do modelo de pagamento por produção para repasse per capita. Esta NOB só foi efetivamente implantada a partir de 1998, quando foi publicada a Instrução Normativa de 1998. Conforme Andrade( ${ }^{(6)}$ esta norma obrigou um "aperfeiçoamento da gestão dos serviços de saúde no país e na própria organização do sistema, visto que o município passou a ser, de fato, responsável imediato pelo atendimento das necessidades e demandas de saúde de sua população e das exigências de intervenções saneadoras em seu território". Mas, neste momento não se conseguiu uma organização dos municípios em caráter complementar, por uma falha na Norma, pois ela foi enfática na aplicação de um novo modelo de atenção baseada na atenção básica e na indução da descentralização, mas mostrou-se insuficiente na reorganização regional dos municípios.

(5) LEVCOVITZ, E.; Lima, L; MACHADO, C., op. cit., pp. 269-291.

(6) ANDRADE, L. O. de; PONTES, R. J.; MARTINS JUNIOR, T. "A Descentralização no marco da reforma sanitária no Brasil'. Rev. Panam Salud Publica, v. 8, n. 1/2, p. 85-91, jul./ago. 2000. 
- NOAS 2001 e 2002: tratam, de forma clara, da organização dos sistemas de saúde e do fortalecimento do papel dos estados como coordenador de um processo articulado de regionalização do SUS, ampliando o conceito de distribuição de recursos per capita, a partir de alocação microrregional, buscando resgatar o que a NOB 1996 deixou a desejar no que diz respeito ao processo de descentralização; busca ainda estabelecer mecanismos para garantia da integralidade da assistência através do fortalecimento da atenção básica. Conforme afirma Mendes ${ }^{(7)}$, a NOAS 2001/2002 parece tentar compensar a NOB 1996, por isso "é hora de se buscar o ponto de equilíbrio, superando a municipalização autônoma, e buscar consolidar a microrregionalização cooperativa".

\begin{tabular}{|c|c|c|c|c|}
\hline Normas & $\begin{array}{l}\text { Racionalidade } \\
\text { Sistêmica }\end{array}$ & $\begin{array}{c}\text { Modelo de } \\
\text { Financiamento }\end{array}$ & $\begin{array}{l}\text { Papel do } \\
\text { Gestores }\end{array}$ & $\begin{array}{l}\text { Processo de } \\
\text { Negociação }\end{array}$ \\
\hline NOB $91 / 92$ & $\begin{array}{l}\text { Igual a pagamento do } \\
\text { prestador público ao } \\
\text { privado } \\
\text { criação e ampliação de } \\
\text { sistemas informatizados } \\
\text { de informação e } \\
\text { centralizados }\end{array}$ & $\begin{array}{l}\text { Repasse condicio- } \\
\text { nado à produção de } \\
\text { serviço }\end{array}$ & $\begin{array}{l}\text { Predominio da } \\
\text { gestão federal } \\
\text { Busca de unificação } \\
\text { do sistema }\end{array}$ & Inexistente \\
\hline NOB/93 & $\begin{array}{l}\text { cria modalidades de } \\
\text { gestão municipal e } \\
\text { estadual, com } \\
\text { requisitos, responsabili- } \\
\text { dades, e prerrogativas } \\
\text { diferentes }\end{array}$ & $\begin{array}{l}\text { Repasse fundo a } \\
\text { fundo a municipios } \\
\text { habilitados, mas } \\
\text { sem romper } \\
\text { totalmente com a } \\
\text { lógica do "pós- } \\
\text { pagamento" }\end{array}$ & $\begin{array}{l}\text { Maior autonomia ao } \\
\text { gestor municipal } \\
\text { Ausência do papel } \\
\text { do Estado }\end{array}$ & $\begin{array}{l}\text { Constituição de um } \\
\text { Grupo Especial de } \\
\text { Descentralização } \\
\text { Instituição das } \\
\text { Comissões } \\
\text { Intergestores - } \\
\text { Tripartite e Bipartite }\end{array}$ \\
\hline NOB/96 & $\begin{array}{l}\text { Normatização da } \\
\text { implantação do SUS } \\
\text { quanto à assistência, à } \\
\text { vigilância sanitária e ao } \\
\text { controle de doenças } \\
\text { Fortalecimento do papel } \\
\text { dos municipios no } \\
\text { Sistema } \\
\text { Fortalecimento dos } \\
\text { mecanismos de apoio à } \\
\text { atenção básica (PAB) } \\
\text { Adoção de políticas de } \\
\text { incentivo } \\
\text { Proposta de elaboração da } \\
\text { Programação Pactuada e } \\
\text { Integradas - PPI }\end{array}$ & $\begin{array}{l}\text { Radicalização do } \\
\text { processo de } \\
\text { transferência fundo } \\
\text { a fundo } \\
\text { Utilização da base } \\
\text { per capita para o } \\
\text { financiamento da } \\
\text { atenção básica } \\
\text { Pagamento de } \\
\text { incentivos }\end{array}$ & $\begin{array}{l}\text { Melhor definição do } \\
\text { papel do Estado }\end{array}$ & $\begin{array}{l}\text { Negociação e } \\
\text { formulação nos } \\
\text { fóruns do Conselho } \\
\text { Nacional de Saúde } \\
\text { e Comissão } \\
\text { Intergestores } \\
\text { Tripartite }\end{array}$ \\
\hline NOAS & $\begin{array}{l}\text { Normatização da } \\
\text { implantação do SUS } \\
\text { quanto à assistência } \\
\text { Ênfase na } \\
\text { regionalização } \\
\text { Instrumentalização da } \\
\text { PPI }\end{array}$ & $\begin{array}{l}\text { Instituição do per } \\
\text { capita de alocação } \\
\text { microrregional } \\
\text { Mecanismo de finan- } \\
\text { ciamento diferencia- } \\
\text { do para o custeio da } \\
\text { alta complexidade }\end{array}$ & $\begin{array}{l}\text { Fortalecimento do } \\
\text { papel do Estado } \\
\text { como coordenador } \\
\text { das relações } \\
\text { intermunicipais }\end{array}$ & $\begin{array}{l}\text { Negociação e } \\
\text { formulação nos } \\
\text { fóruns do Conselho } \\
\text { Nacional de Saúde } \\
\text { e Comissão } \\
\text { Intergestores } \\
\text { Tripartite }\end{array}$ \\
\hline
\end{tabular}

Fonte: DGA/SAS/MS

(7) MENDES, Eugênio Vilaça. "Os grandes dilemas do SUS". I. Salvador, BA: Casa da Qualidade Ed., 2001, t. 1. 
A proposta da regionalização baseia-se na constatação de que, isolados, os sistemas de saúde municipais dificilmente são suficientes para garantir a integralidade das ações de saúde para os seus munícipes. Por isto, destaca-se a importância de vários sistemas de saúde municipais buscarem formas de tornarem-se complementares, forma de organização sob a qual seria possível otimizar os serviços de saúde existentes em cada um dos municípios, respeitando a escala adequada e o direito constitucional de todos os cidadãos terem o acesso garantido a todas as suas necessidades de saúde, alcançando, desta forma, o princípio da integralidade da assistência.

Percebe-se, apesar da NOAS propor a organização dos espaços microrregionais, que esta norma não induziu a efetivação destes espaços de forma a torná-los resolutivos. Exemplo disso foi o fato de não haver microrregiões organizadas a ponto de alcançarem a qualificação conforme a NOAS preconiza. Parece-nos possível perceber um movimento pendular de centralização e descentralização no âmbito do SUS.

O tema regionalização foi o norte desta norma, pois se alcançou um consenso nas instâncias de negociação que já se havia avançado consideravelmente no campo dos processos de descentralização.

Segundo Mendes $^{(8)}$ é praticamente consenso de que há uma crise nos sistemas de saúde; no entanto, há profundas divergências quanto às formas de superá-la. Apesar da crise há também consenso de que os princípios e diretrizes definidas pelo SUS são as melhores alternativas para organizar a atenção à saúde no Brasil. Entre as diretrizes, a organização regionalizada do sistema de saúde é de suma importância para o acesso dos cidadãos a todas as ações e serviços de saúde e na busca de garantia integralidade e à universalidade proposta pela Constituição. Destaca-se a importância do planejamento neste processo.

Segundo Matus $^{(9)}$ não há governo eficaz sem dispor de métodos poderosos de planejamento. A NOAS, para os gestores comprometidos, permite instrumentalizar o processo de planejamento na saúde, tendo como uma das diretrizes centrais, buscar de forma consensuada e pactuada, a organização dos espaços microrregionais de saúde.

O objetivo da NOAS/SUS 01/01 é "promover maior eqüidade na alocação de recursos e no acesso da população às ações e serviços de saúde em todos os níveis de atenção"(10). Esta Norma é dividida em três capítulos: regionalização, fortalecimento da capacidade de gestão no SUS e critérios de habilitação de municípios e estados.

(8) MENDES, Eugênio Vilaça, op. cit.

(9) MATUS, Carlos. "Adeus, Senhor Presidente: governantes governados". Trad. de Luis Felipe Rodriguez del Riego. São Paulo: Ed. FUNDAP, 1996.

(10) BRASIL, Ministério da Saúde, Regionalização da Assistência à Saúde: aprofundando a descentralização com eqüidade no acesso - Norma Operacional de Assistência à Saúde/NOASSUS 01/01, Série A. Normas e Manuais Técnicos, Brasilia, DF, n. 116, p. 14, 2001. 
O Capítulo da Regionalização estabelece "o processo de regionalização como estratégia de hierarquização dos serviços de saúde e de busca de maior eqüidade (11)". "Deve contemplar uma lógica de planejamento integrado, compreendendo as noções de territorialidade, a identificação de prioridade de intervenção e de conformação de sistemas funcionais de saúde, não necessariamente restritos à abrangência municipal, mas respeitando seus limites como unidade indivisível, de forma a garantir o acesso dos cidadãos a todas as ações e serviços necessários para a resolução de seus problemas de saúde, otimizando os recursos disponiveis"(12).

Dentre as normas publicadas, há a percepção de que esta foi a que mais induziu os processos de planejamento, seja para a elaboração do Plano Diretor de Regionalização, seja para o Plano Diretor de Investimento. Por mais críticas e dificuldades que os gestores possam ter durante a elaboração destes, observa-se que os atores puderam ter através deste instrumento a capacidade e a oportunidade de realizar diagnósticos e identificar as dificuldades. Mas como uma marca do planejamento estratégico situacional, mantém-se a dificuldade de operacionalização do que foi planejado.

Conforme explica Cecilio(13) (apud Pinheiro, 2002), deve-se considerar as necessidades de saúde intersetorialmente, que podem ser "a busca de algum tipo de resposta para as más condições de vida que a pessoa viveu ou está vivendo (do desemprego à violência no lar), a procura de um vínculo (a)efetivo com algum profissional, a necessidade de ter maior autonomia no modo de andar a vida, ou mesmo, de ter acesso a alguma tecnologia de saúde disponivel, capaz de melhorar e prolongar sua vida. Está tudo ali na 'cestinha de necessidades', precisando ser, de alguma forma, escutado e traduzido, pela equipe. Assim, a integralidade da atenção, no espaço singular de cada serviço de saúde, poderia ser definida como o esforço da equipe de saúde de traduzir e atender, da melhor forma possível, tais necessidades, sempre complexas mas, principalmente, tendo que ser captadas em sua expressão individual".

O Capítulo que diz respeito ao Fortalecimento da Capacidade da Gestão, traz instrumentos que pretendem organizar e fortalecer o planejamento dos sistemas de saúde, entre eles:

a Programação Pactuada e Integrada - PPI, que é um instrumento de alocação de recursos entre os municípios e os estados. Através da PPI inicia-se um processo de negociação das referências, como forma de garantia de acesso integral. Os gestores, de acordo com o PDR, definem onde serão alocados os recursos de seus cidadãos. É estabelecido um per capita para todos os procedimentos. Este recurso financeiro é destinado a cada munícipe e o acompanha de acordo com o município

(11) Id. Ibid., p. 32.

(12) Id., loc. cit.

(13) PINHEIRO, R.; MATTOS, Ruben Araújo. "Construção da integralidade: cotidiano, saberes e praticas em saúde". Rio de Janeiro: IMS/ABRASCO, 2003. v. 1, p. 228. 
em que servirá de referência no PDR. A Programação Pactuada e Integrada também pode ser identificada como um instrumento de planejamento para alocação de recursos financeiros. Para sua elaboração é necessário a identificação de parâmetros de necessidade. Por mais "frustrante" que o processo possa ser - ao compatibilizar os recursos financeiros aos parâmetros de necessidades - nunca há recursos suficientes - foi um dos únicos momentos em que os estados e municípios se reuniram para planejar a alocação de recursos financeiros a partir de uma leitura da situação e de uma pactuação entre os atores envolvidos. A PPI traz como referência a discussão de parâmetros de necessidade. Houve em 2002 a publicação da Portaria GM n. 1.101, que publicou os resultados de uma consulta pública, realizada durante o ano de 2001, sobre as necessidades de saúde da população baseada nos procedimentos, sem problematizar, contextualizar, ou mesmo discutir a organização dos serviços de acordo com a escala adequada;

e os instrumentos de acompanhamento da garantia de acesso Termo de Compromisso para Garantia de Acesso. Para que o acesso seja garantido, os gestores responsabilizam-se pela garantia do acesso aos munícipes, de acordo com o fluxo definido no PDR e na PPI. Estes instrumentos foram identificados como frágeis, pois são assumidos compromissos que são muitas vezes difíceis de serem cumpridos, pois há dificuldades de negociação e pactuação entre os gestores, que sentem a necessidade de priorizar o atendimento à população do seu próprio município, já que os recursos financeiros são finitos;

e do processo de Controle, Regulação e Avaliação. Pela primeira vez se trabalhou com os processos de controle e avaliação como instrumentos de fortalecimento da gestão, de forma a otimizar os recursos financeiros e a organizar os fluxos definidos, através da regulação. $O$ conceito de regulação que se propõe na NOAS 2002 é o da regulação assistencial propriamente dita, não se trabalha o conceito mais amplo da regulação, conforme proposta da atual gestão do Ministério da Saúde, que vem trabaIhando todos os instrumentos para o fortalecimento da capacidade de gestão como orientadores da regulação, desde PPI até contratos.

O último capítulo reorganiza os critérios e prerrogativas da habilitação de estados e municípios, sendo diferente das NOB's anteriores, pois consideram, além de outros requisitos, o perfil assistencial dos municípios, de acordo com o papel a ser desempenhado por ele no Plano Diretor de Regionalização.

A NOAS prevê dois tipos de habilitação, conforme a capacidade resolutiva do município:

$\square$ gestão plena de atenção básica ampliada: onde se estabelecem cinco áreas estratégicas - saúde da mulher, da criança, saúde bucal, controle da diabetes e eliminação da hanseníase, além da obrigatoriedade de possuir eletrocardiograma e posto de coleta;

$\square$ gestão plena do sistema municipal: onde se preconiza que o município ofereça um mínimo de procedimentos da média complexidade, incluindo ultra-sonografia, radiologia e odontologia especializada. 
Com paração entre habilitação em GPSM com GPAB-A em 2003 - total Brasil

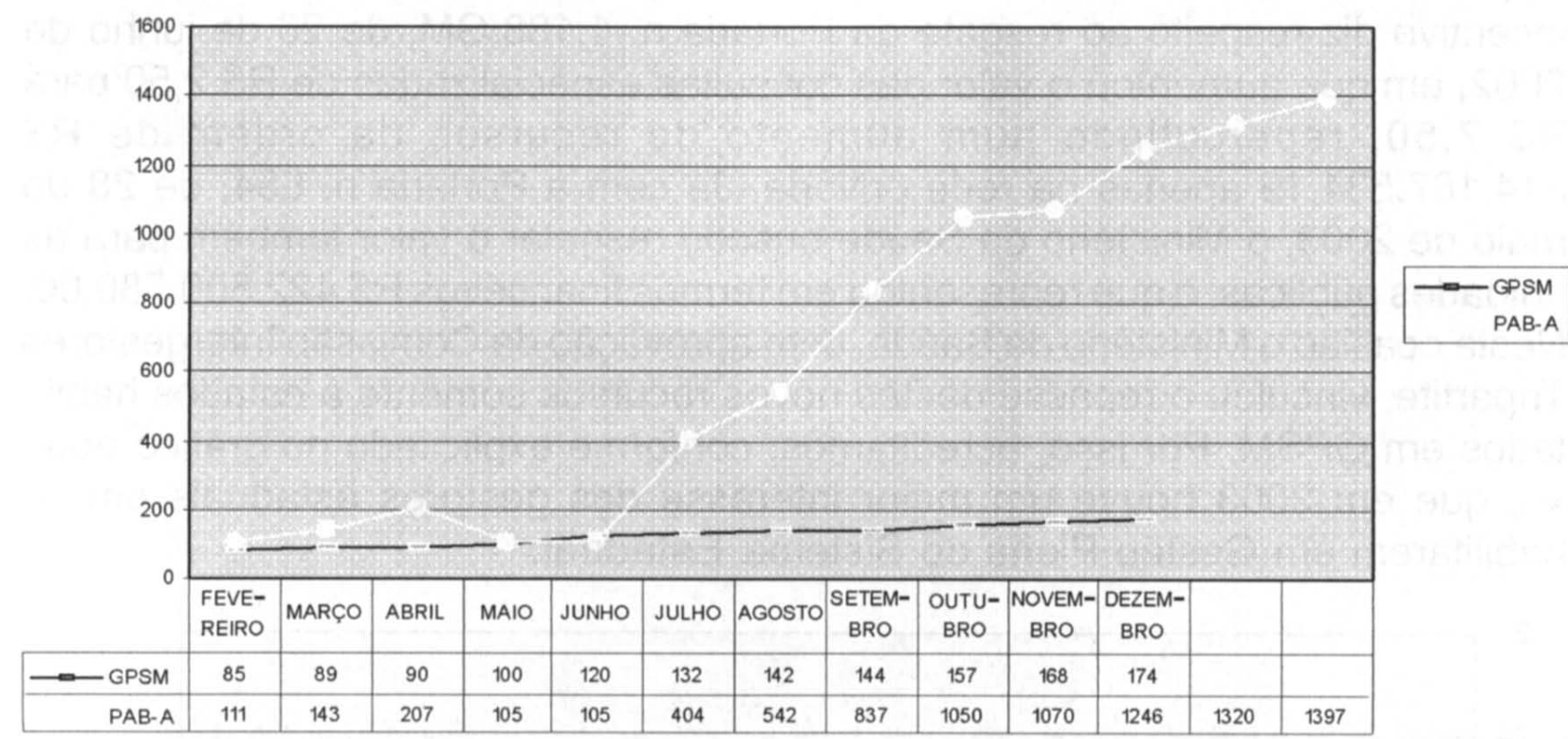

Fonte: ST/CIT/DAD/SE/MS

Pode-se observar que a partir de julho de 2003 houve um incremento nas habilitações em GPAB-A no país, quando pudemos levantar as seguintes situações:

- Aumento no incentivo financeiro, que passou o PAB fixo de 10,50 para 12,00 para os municípios que habilitassem em PAB-A;

- Flexibilização nos critérios de habilitação, quando ficou estabelecido um prazo para que os municípios providenciassem posto de coleta e eletrocardiograma, considerados critérios para habilitação. Este prazo foi adiado três vezes e os municípios ainda não cumpriram. Por isto questionamos se este é um critério efetivamente importante, ou deve-se pensar em outra lógica para garantir as ações da atenção básica.

As habilitações em Gestão Plena de Sistema Municipal não apresentaram crescimento, onde pode-se supor que não houve incentivo, financeiro ou não, para diferenciar esta habilitação. O comando único, critério que diferencia esta modalidade de habilitação da utilizada pela NOB/ 96 vem dificultando os pactos locais, contribuindo também para o pequeno número de municípios pleiteantes nesta modalidade.

A habilitação dos estados em Gestão Plena do Sistema foi mais efetiva a partir dos critérios da NOAS. Apesar dos instrumentos de comprovação das habilitações serem semelhantes aos da NOB, pode-se perceber que houve um fortalecimento no papel das Secretarias Estaduais de Saúde na NOAS, principalmente na condução dos processos. E em junho 
de 2003 houve um incentivo financeiro, de alta monta em alguns estados, o que acreditamos ter sido indutor para que os estados se habilitassem. Este incentivo diz respeito ao resgate da Portaria n. 1.188/GM, de 26 de junho de 2002 , em que aumentou o valor das consultas especializadas de $R \$ 2,50$ para $R \$ 7,50$, repercutindo num aumento de recursos da ordem de $R \$$ $314.167 .534,19$ apenas na rede privada. Já com a Portaria n. 654, de 28 de maio de 2003, o Ministério da Saúde buscou resgatar o valor também para as unidades públicas, o que representou em termos financeiros $R \$ 422.500 .780,00$. Nesta ocasião o Ministério da Saúde, com aprovação da Comissão Intergestores Tripartite, vinculou o repasse destes novos recursos somente a estados habilitados em GPSM. Por isso, acreditamos, conforme explicitado no gráfico abaixo, que em 2003 houve um maior interesse dos gestores estaduais em se habilitarem em Gestão Plena do Sistema Estadual.

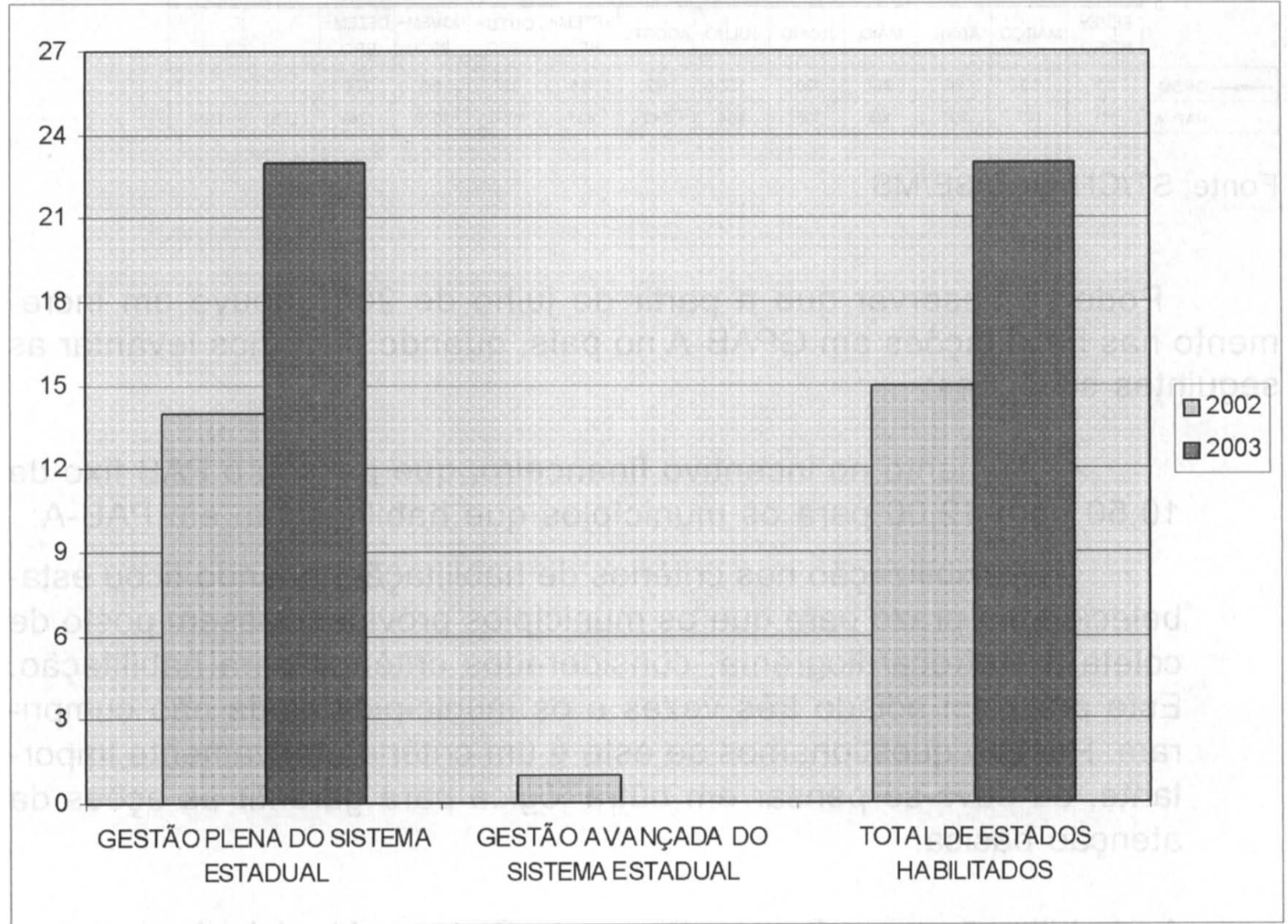

Percebemos, assim, que a publicação da NOAS permitiu um grande avanço no que diz respeito ao processo de planejamento em saúde e na regionalização das ações de saúde. Notou-se um grande movimento no processo de descentralização dos estados, já que estes na sua maioria habilitaram segundo os critérios previstos nesta norma. Considerando a necessidade de um importante elemento para a implementação da regionalização enquanto instrumento para a melhoria do acesso e da qualidade do Sistema Único de Saúde, a NOAS é uma ferramenta que deve ser aperfeiçoada no que tange a este aspecto. Talvez avançamos para um novo momento na normatização do SUS, isto é, um momento em que os pactos superem as normas. 


\section{REFERÊNCIAS BIBLIOGRÁFICAS}

ANDRADE, L. O. de; PONTES, R. J.; MARTINS JUNIOR, T. "A Descentralização no marco da reforma sanitária no Brasil". Rev. Panam Salud Publica, v. 8 , n. 1/2, pp. 85-91, jul./ago. 2000.

BRASIL, Ministério da Saúde, "Regionalização da Assistência à Saúde: aprofundando a descentralização com eqüidade no acesso - Norma Operacional de Assistência à Saúde/NOAS-SUS 01/01, Série A". Normas e Manuais Técnicos, Brasília, DF, n. 116, p. 14, 2001.

GOULART, F. de A. "Esculpindo o SUS a golpes de portarias - considerações sobre o processo de formulação das NOB's". (comentário ao texto de Levcovitz et al., 2001). Ciência e Saúde Coletiva, v. 6, n. 2, pp. 292$298,2001$.

LEVCOVITZ, E.; Lima, L; MACHADO, C. "Política de Saúde nos anos 90: relações intergovernamentais e o papel das Normas Operacionais Básicas". Ciência \& Saúde Coletiva, v. 6, n. 2, pp. 269-291, 2001.

MATUS, Carlos. "Adeus, Senhor Presidente: governantes governados". Trad. de Luís Felipe Rodriguez Del Riego. São Paulo: Ed. FUNDAP, 1996.

MENDES, Eugênio Vilaça. "Os grandes dilemas do SUS". I. Salvador, BA: Casa da Qualidade Ed., 2001, t. 1.

PINHEIRO, R.; MATTOS, Ruben Araújo. "Construção da integralidade: cotidiano, saberes e praticas em saúde". Rio de Janeiro: IMS/ABRASCO, 2003. v. 1, p. 228.

VIANA, A. L. D., HEIMANN, L. S., LIMA, L. D. de et al. "Mudanças significativas no processo de descentralização do sistema de saúde no Brasil". Cad. Saúde Pública, supl. v. 18, 2002, pp. 139-151. 


\title{
Tema em Debate / Argument
}

\author{
APRESENTAÇÃO / PRESENTATION
}

Dyrceu A. Dias Cintra Junior ${ }^{(*)}$

A seção Tema em debate da Revista de Direito Sanitário traz, em três artigos, importantes considerações sobre a Reforma Psiquiátrica.

A Lei n. 10.216/2001, inspirada pelo Movimento da Luta Antimanicomial, buscou abrir caminho para a superação do modelo hospitalocêntrico, baseado na exclusão social do doente mental, que caracterizava a legislação anterior.

Uma vez aprovada, muitas questões se põem.

Seria boa a "desconstrução" do sistema até agora vigente, transformando vagas de internação em vagas de serviço aberto (centros de atenção psicossocial, as pensões protegidas, lares abrigados, hospital-dia, hospital-noite, emergência psiquiátrica, serviço psiquiátrico no posto de saúde e outros)?

A nova legislação, aprovada sob o pressuposto do prestígio aos direitos humanos, abolindo a secular e odiosa prática do isolamento, significará mesmo um avanço no tratamento da questão do sofrimento mental?

A sociedade e a família estão preparadas para os desafios do novo modelo, em que o contato com o doente mental é maior? Estão elas capacitadas para o papel de recuperação social que lhes é destinado?

Os autores dos três artigos sobre o assunto publicados nesta revista abordam tais questões, exprimindo pontos de vista divergentes.

Renoir da Silva Cunha, membro do Ministério Público do Estado do Rio Grande do Sul, é autor do texto "Direito Sanitário, Ministério Público e Reforma Psiquiátrica".

(*) Magistrado do Tribunal de Justiça do Estado de São Paulo, fundador e ex-presidente da Associação Juizes para a Democracia e membro do Instituto Brasileiro de Ciências Criminais. Endereço eletrônico: dycintra@bol.com.br 
Procura demonstrar que o paradigma a ser superado, no sentido de dar cidadania ao portador de sofrimento mental, assegurando-Ihe existência digna, não se restringe à supressão dos manicômios, exigindo, sim, um esforço mais amplo para superar a cultura da exclusão e da segregação solidificado nas estruturas sociais.

Nesse passo, enfrenta a questão da efetividade da reforma, preconizando que o avanço na linha antimanicomial não pode implicar no retrocesso da qualidade, humanização, acesso e controle social sobre o problema, destacando o papel do Ministério Público no sentido de fiscalizar as internações compulsórias, que prosseguem sendo possíveis em casos mais graves, inclusive quanto à legalidade e dignidade das instalações, e zelar pela qualidade em geral dos serviços de relevância pública, que exprimem interesses coletivos, onde se incluem as ações de saúde.

De fato, membros do Movimento da Luta Antimanicomial têm ressaltado a necessidade de cuidar para que as desinternações sejam efetivamente assistidas, evitando o abandono de pessoas que necessitam de tratamento em outro ambiente. Ao bloqueio de uma vaga em hospital psiquiátrico deve corresponder a criação da vaga correspondentes no serviço aberto.

Outra questão importante, tocada por Renoir é de ordem cultural: é preciso empenhar esforços no sentido de demonstrar as vantagens de um maior contato do doente mental com a sociedade.

Há efetivamente que superar preconceitos de uma população que se acostumou a pensar no doente mental como uma estranha simbiose de um ser perigoso e incapaz. A família precisa ser capacitada, material e intelectualmente, para que possa dar atenção aos seus doentes.

A abordagem de Valentim Gentil, médico psiquiatra, professor titular da Faculdade de Medicina da USP, no artigo "A Ética e os Custos Sociais da Reforma Psiquiátrica", se aproxima da já referida, apenas quanto ao temor de que a desinternação que decorre da nova política se dê sem implementação dos sistemas alternativos de atendimento, deixando muitos dos doentes "abandonados à própria sorte, presos em suas casas ou 'morando' nas ruas".

Quanto ao mais, ao contrário, o autor não vê virtudes da reforma, acusando-a de engajada em movimentos sociais, mais que voltada para as necessidades dos doentes, e de promover uma "desconstrução" da moderna Psiquiatria.

Aponta, ademais, falhas na Universidade, que ainda não se mobilizou de forma coordenada para contribuir em busca de soluções, bem como o desconhecimento da extensão do problema na sociedade brasileira, afirmando, que entre os presos, por exemplo, muitos portadores de doença mental estão sem qualquer atenção psiquiátrica, submetidos a sofri- 
mentos extraordinários em conseqüência de sua incapacidade de entender e respeitar adequadamente as exigências disciplinares das instituições em que estão.

No terceiro artigo, "Direito Penal da Loucura: Medida de Segurança e Reforma Psiquiátrica", Paulo Vasconcelos Jacobina, procurador da república, depois de fazer uma retrospectiva histórica e filosófica da loucura, expõe as contradições entre a Lei n. 10.216/2001 e a legislação penal.

A medida de segurança, ao contrário do que devia ser, tem na prática caráter punitivo, submetida que está ao Sistema Penitenciário e não ao Sistema Único de Saúde, diz ele, preconizando uma nova abordagem jurídica da questão em matéria criminal, a partir do próprio alicerce filosófico do direito penal: os fundamentos da função social do direito de punir.

Com efeito, além do tratamento eminentemente penal que caracteriza a aplicação de medida de segurança, não se justificam, diante da nova abordagem do tema, internações com prazo indeterminado.

Os textos tratam de questões importantes e polêmicas. Participe o leitor desse debate. 